\title{
Autologous semitendinosus tendon graft could function as a meniscal transplant
}

\author{
Erik Rönnblad $^{1}$ (1) $\cdot$ Pierre Rotzius $^{2} \cdot$ Karl Eriksson $^{2}$
}

Received: 24 February 2021 / Accepted: 4 May 2021 / Published online: 8 June 2021

(c) The Author(s) 2021

\begin{abstract}
Purpose Meniscectomy results in poor knee function and increased risk for osteoarthritis. Meniscal allograft transplantation is not widely used due to costs and availability. The semitendinosus tendon (ST) has the potential to remodel and revascularize in an intraarticular environment, such as ACL reconstruction. The objective for this pilot study was to investigate whether the ST graft could function as a meniscal transplant.

Methods The ST was doubled and sutured with running sutures and pull-out sutures in each end. Bone tunnels were used for root anchorage and the graft was sutured with allinside, inside-out and outside-in technique. The pull-out sutures were fixed over a button. Partial weight bearing was allowed with limited range of motion in a brace for the first 6 weeks. Evaluation was assessed using clinical examination, radiology and patient reported outcome.

Results A total of seven patients have been included between January 2018 and June 2020. Six medial transplants and one lateral transplant were performed. Mean age was 29 years. Four patients had completed the 12 -month follow-up. Improvements were noted for IKDC Global Score, KOOS pain subscale and Lysholm. MRI indicated that the transplant become more wedge-like with visible roots and minor protrusion.

Conclusions Even though this is primarily a technical report the follow-up data indicate that the transplant survives and adapts in shape and capabilities to an original meniscus. There were no adverse events and the patients seem to improve in terms of pain and quality of life.
\end{abstract}

Keywords Meniscal transpantation $\cdot$ Meniscus repair $\cdot$ Tendon autograft

\section{Introduction}

Meniscal injuries are common, and removal of meniscal tissue has been linked to poorer knee function and a significantly increased risk of developing osteoarthritis $[1,3$, 21, 27-29, 35, 39]. Meniscal repair is favorable, however, not always achievable. Different implants have been suggested to substitute a removed meniscus [37, 38]. Despite promising early results $[11,41]$, scaffolds are not widely used today. Meniscus allograft transplantation (MAT) has been performed for many years [24, 31, 43]. Several studies have reported relatively successful results following MAT

Erik Rönnblad

erikronnblad@gmail.com

1 Capio Artro Clinic, Stockholm Sports Trauma Research Center/Karolinska Institutet, Valhallavägen 91, 11486 Stockholm, Sweden

2 Södersjukhuset/KISÖS, Stockholm, Sweden
$[9,10,12,15,18-20,23,26,32,34,40,42]$ even though its chondro-protective effect remains unclear [30, 32, 33, 36]. Patient selection is crucial and sizing issues, as well as costs and availability, are hinders that have limited the widespread use of this method [4]. Furthermore, in some countries, such as Japan, allograft tissue is not widely available.

Kohn et al. [16] have reported chondroprotective effects using a patellar tendon autograft as a meniscal transplant after meniscectomy in an animal study. They also reported successful results for both healing and cartilage protection in a clinical study using part of the quadriceps tendon as meniscal autograft transplant $[16,17]$. Twelve-month results were reported to be promising but no detailed data has been published.

Johnson and Feagin presented a pilot study in 2000, where tendon autografts were used as a lateral meniscal transplant [14]. No clinical improvement or preservation of the joint space was observed. However, the patients had loss of lateral joint space and profound genu valgus at the time 
of surgery, suggesting that the patients were rather cases for knee replacement [14]. The semitendinosus tendon has previously been transplanted as a new meniscal rim for attachment of a collagen implant with successful outcomes [2].

The semitendinosus tendon is a well-known graft that is relatively easy to harvest with low harvest site morbidity. It has biological properties with potential to remodel and revascularize in an intraarticular environment, such as in ACL reconstruction $[13,16]$.

The hypothesis for this study is that the semitendinosus tendon graft can function as a meniscal transplant after total or subtotal meniscectomy, and that patients receiving a neomeniscus with semitendinosus tendon experience less post meniscectomy symptoms.

\section{Materials and methods}

The study was approved by the Regional ethical committee (Karolinska Institutet ID number: 2016/281-31/1).

Patients were assessed for eligibility using an a priori set of patient inclusion criteria: age 20-50 years, previous history of subtotal or total meniscectomy medially or laterally, no significant osteoarthritic changes on radiographs (Ahlbäck 0-1), alignment on long alignment films producing hip-knee-angle (HKA) of maximum 3 degrees increased stress in the affected compartment, post meniscectomy symptoms (i.e., medial or lateral pain accentuated with weight bearing), no smoking. Furthermore, ligamentous stability was required, and in cases of ACL insufficiency a concomitant ACL reconstruction or revision was performed.

All patients received thorough counseling regarding the surgical procedure, its experimental nature, expectations and treatment options available.

\section{Evaluation criteria}

Successful outcome was considered improvement of knee function and quality of life for the patient according to patient reported outcome measures (PROMs). PROMs used were Global score, Knee Injury and Osteoarthritis and Outcome Score (KOOS), Lysholm score and activity score according to Tegner. Questionnaires were answered preoperatively and $3,6,12$ and 24 months postoperatively.

Another criterion for success was maintenance of transplant integrity. This was assessed through MRI after 3, 6, 12 and 24 months. Further radiological examination was weight bearing radiographs and HKA and traditional radiography after 6 months.

Clinical assessment including range of motion (ROM), tenderness, effusion and laxity were performed at 3, 6, 12 and 24 months.

\section{Surgical technique}

\section{Arthroscopic preparation}

All surgical procedures were performed by the senior author. Antibiotic prophylactics was administered using i.v. Cloxacillin ${ }^{\circledR} 2 \mathrm{~g}$, and the graft was imbedded in a Vancomycin ${ }^{\circledR}$ swab. In cases of ACL insufficiency a reconstruction or revision was performed.

Any remaining remnants of the native meniscus were removed and the menisculocapsular junction was debrided to obtain a fresh bleeding surface. Pie-crust of the MCL was performed when needed.

\section{Graft preparation}

After harvesting, the graft was cleaned of any muscle tissue and the flat proximal part of the tendon was folded over the distal round part creating a double-stranded loop (Fig. 1). The folded flat part of the tendon was then sutured with a running 2.0 Fiberwire ${ }^{\circledR}$ suture embedding and catching the round part. The two knots were placed in each end of the folded graft to avoid interference with the intraarticular surface. A number 2 suture-tape was used to create a Chinese finger trap of the free strands in the opposite end of the graft. The length of the grafts varied between 12 and $15 \mathrm{~cm}$ and diameter varied between 6 and $7 \mathrm{~mm}$.

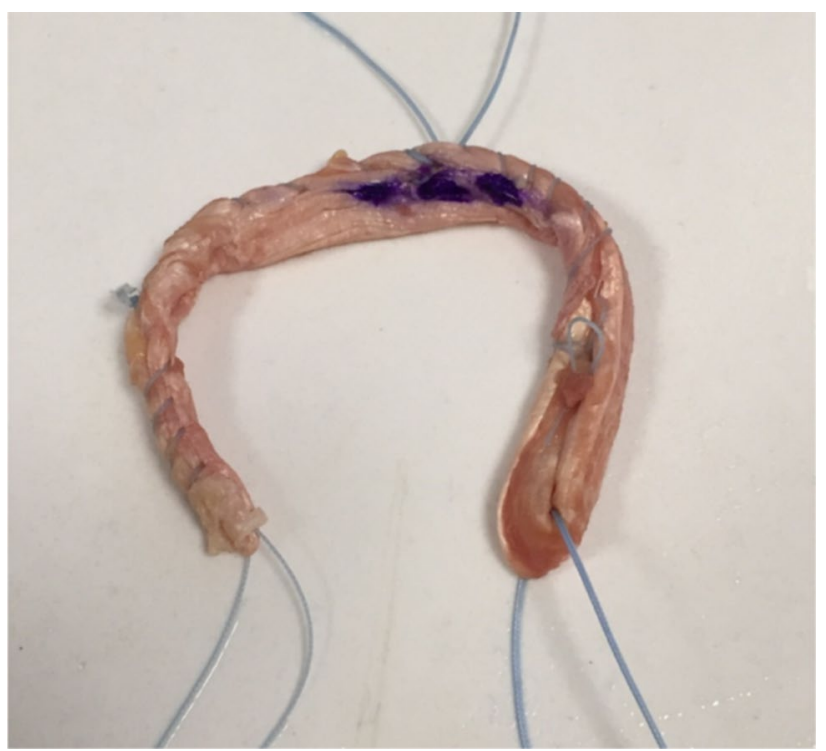

Fig. 1 Double-folded semitendinosus tendon with sutures 


\section{Tunnels}

The root tunnels were created as close to the anatomic position as possible in a retrograde fashion using the meniscus root guide and flip-cutter (Arthrex $\left.{ }^{\circledR}\right)$ with dimensions corresponding to the graft size.

\section{Insertion and placement}

The tendon graft was inserted through an accessory portal and the folded end of the graft was pulled into the posterior root tunnel. The graft was then pushed in place along the capsular border using a blunt instrument. The sutures from the other graft end were retrieved and pulled down the anterior root tunnel. Vertical sutures were used around the graft (Fig. 2). The inside-out and outside-in sutures were not fixed to the capsule until tension had been applied by pulling on the anterior and posterior root sutures.

\section{Postoperative rehabilitation protocol}

Partial weight bearing was allowed for the first 6 weeks. A hinged knee brace was used, set at $0-30^{\circ}$ for 3 weeks, $0-60^{\circ}$ for 3 weeks, $0-90^{\circ}$ for 2 weeks and unrestricted range of motion in the brace for another 4 weeks. The protocol follows the standard procedure following a suture of a sutured meniscus bucket-handle tear apart from the partial weight bearing. Weight bearing while squatting was restricted the first 4 months (Figs. 3 and 4).

\section{Statistical analysis}

Due to the low number of patients the results are only presented in a descriptive fashion.

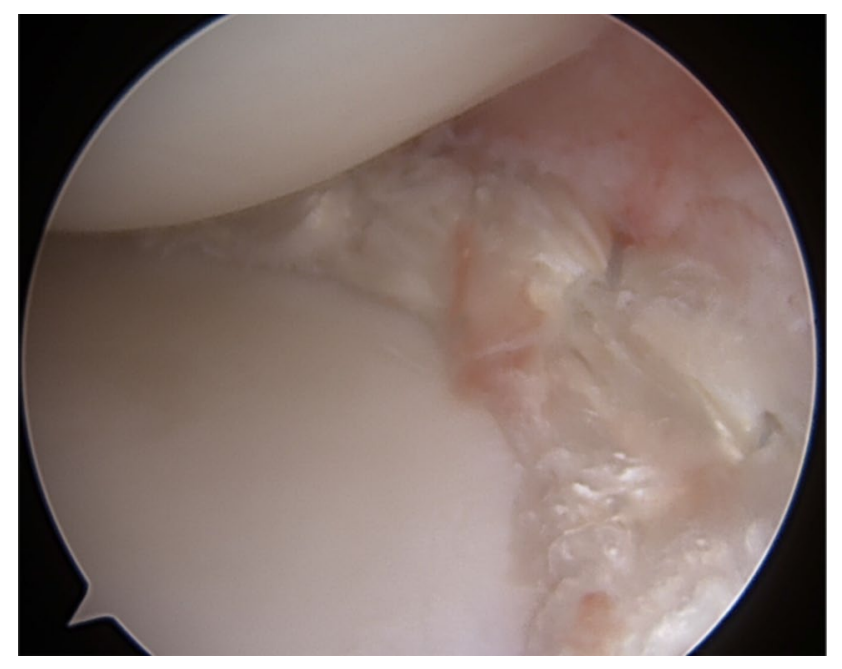

Fig. 2 Medial meniscus transplant in position

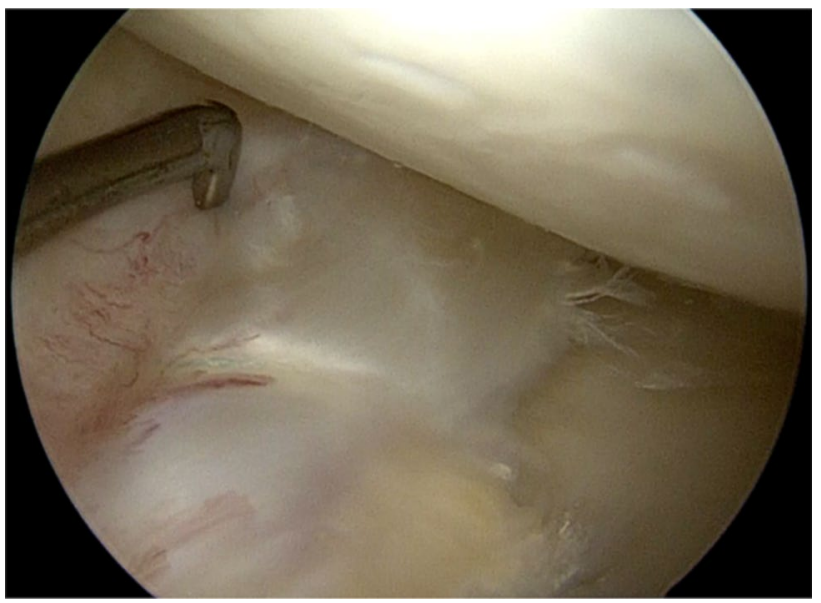

Fig. 3 Re-arthroscopy 6-month post-operatively. Capillary ingrowth noted along the circumference of the neomeniscus

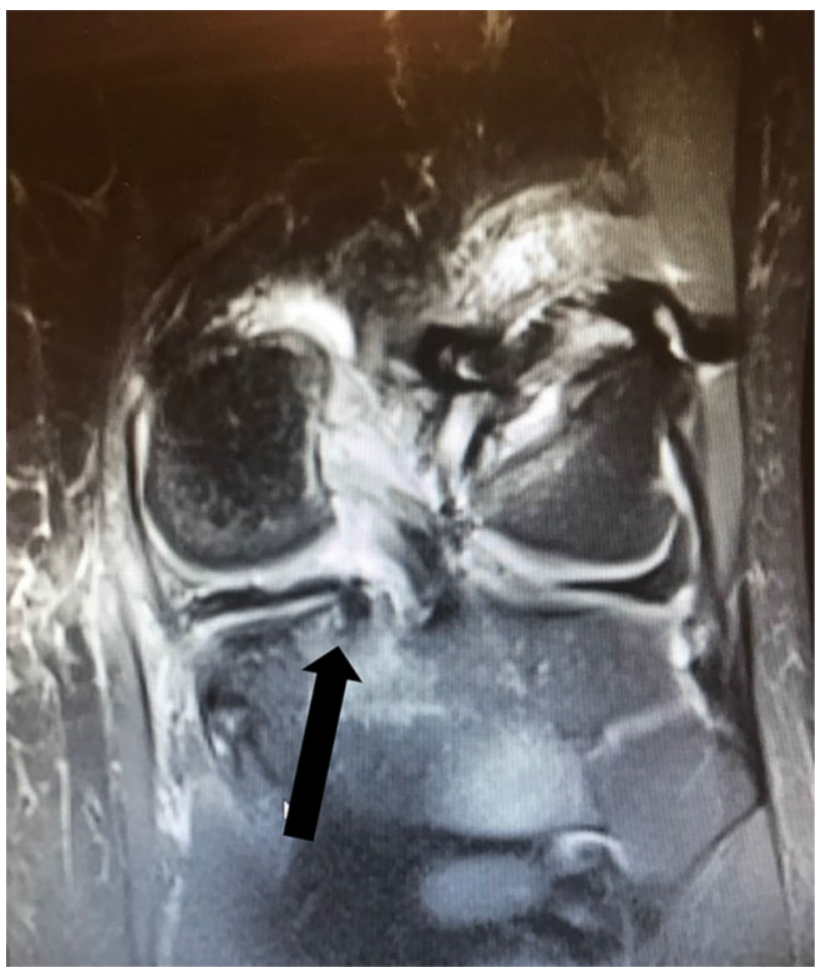

Fig. 4 Frontal view of MRI T2-scan showing a medial meniscus transplant with the posterior root attachment (arrow) 
Table 1 Demographic characteristics

\begin{tabular}{llllrl}
\hline $\begin{array}{l}\text { Gender } \\
\text { (female:male) }\end{array}$ & $\begin{array}{l}\text { Age (median, } \\
\text { range) }\end{array}$ & Side (right:left) & $\begin{array}{l}\text { Meniscus } \\
\text { (medial:lateral) }\end{array}$ & $N$ of ACLR & $\begin{array}{l}\text { BMI } \\
\text { (median, } \\
\text { range) }\end{array}$ \\
\hline $6: 1$ & $28(23-41)$ & $3: 4$ & $6: 1$ & 4 & $\begin{array}{c}25.4 \\
(22.1- \\
37.2)\end{array}$ \\
\hline
\end{tabular}

$A C L R$ anterior cruciate ligament reconstruction; BMI body mass index

**Patient number two was excluded from the 12-month analysis due to failure with subtotal resection of the neomeniscus

Table 2 Global score

\begin{tabular}{llll}
\hline $\begin{array}{l}\text { Preop } \\
N=7\end{array}$ & $\begin{array}{l}\text { months } \\
N=7\end{array}$ & $\begin{array}{l}6 \text { months } \\
N=7\end{array}$ & $\begin{array}{l}12 \text { months } \\
N=4\end{array}$ \\
\hline 3 & 3 & 5 & 6.5 \\
\hline
\end{tabular}

Data are reported as median (range)

**Patient number two was excluded from the 12-month analysis due to failure with subtotal resection of the neomeniscus

Statistical analyses were conducted using IBM SPSS Statistics version 23 (SPSS Inc, Armonk, New York, USA).

\section{Results}

Seven patients were included between January 2018 and June 2020. Baseline characteristics are presented in Table 1. Results are presented on group level. No early surgical complications, such as infections or deep vein thrombosis (DVT), were registered in any of the cases.

Four patients had completed the 12-month followup. Global score, KOOS pain subscale, and Lysholm all increased.

\section{Global score}

For the four patients with a retained meniscus transplant, there was an improvement in global score at 12-month follow-up (Table 2).

\section{KOOS}

The mean KOOS scores showed an improvement compared to preoperative. KOOS data is detailed in Table 3.

\section{Lysholm score}

There was an improvement in Lysholm at the 12-month follow-up compared to the preoperative values. Lysholm values are presented in Table 4.
Table 3 KOOS

\begin{tabular}{lllll}
\hline & $\begin{array}{l}\text { Preoperative } \\
N=7\end{array}$ & $\begin{array}{l}3 \text { months } \\
N=7\end{array}$ & $\begin{array}{l}6 \text { months } \\
N=7\end{array}$ & $\begin{array}{l}12 \text { months } \\
N=4\end{array}$ \\
\hline Symptoms & $45 \pm 14$ & $50 \pm 14$ & $55 \pm 15$ & $65 \pm 7$ \\
Pain & $51 \pm 15$ & $70 \pm 5$ & $72 \pm 18$ & $78 \pm 8$ \\
ADL & $62 \pm 26$ & $77 \pm 14$ & $80 \pm 25$ & $88 \pm 10$ \\
Sports/Rec & $20 \pm 30$ & $30 \pm 32$ & $28 \pm 28$ & $30 \pm 24$ \\
QoL & $16 \pm 20$ & $22 \pm 12$ & $28 \pm 20$ & $38 \pm 5$ \\
\hline
\end{tabular}

Data are reported as mean $\pm \mathrm{SD}$

$A D L$ activities in daily living; Sports/Rec, sports and recreation; $S D$ standard deviation; $Q o L$ quality of life

Table 4 Lysholm score

\begin{tabular}{llll}
\hline $\begin{array}{l}\text { Preoperative } \\
N=7\end{array}$ & $\begin{array}{l}3 \text { months } \\
N=7\end{array}$ & $\begin{array}{l}6 \text { months } \\
N=7\end{array}$ & $\begin{array}{l}12 \text { months } \\
N=4\end{array}$ \\
\hline $41 \pm 14$ & $62 \pm 10$ & $65 \pm 21$ & $73 \pm 10$ \\
\hline
\end{tabular}

Data are reported as mean $\pm S D$

\section{Radiographic assessment}

The signal intensity in the grafts on MRI was predominantly increased and, in some cases, slight medial protrusion was noted. The root anchoring of the graft was clearly seen in all cases. In all cases the neomeniscus presented in a wedge shaped, meniscus-like fashion.

\section{Discussion}

The most important finding of the study was that early results indicate promising potential for the use of semitendinosus tendon as a meniscus transplant. It is important to emphasize that this paper is primarily a technical report on the use of an autologous semitendinosus tendon graft as a neomeniscus. The early follow-up data indicate that the transplant could survive, transform and remodel to a meniscus-like structure with ingrowth to the surrounding capsular tissue. As such it could potentially function as a meniscus 
substitution. Despite a small number of patients and as yet short follow-up period, data also indicated that most patients experienced an improvement in terms of weight bearing pain and quality of life.

\section{Transplant integrity}

MRI scans at 12-month follow-up show signs that the transplant transforms in shape and becomes more wedge like, though with increased signal in most projections (Fig. 5). The anchorage of the roots is visible (Fig. 4). The volume of the transplant remains to be analyzed and compared to normal menisci.

One patient was excluded due to a general progression of osteoarthritis and failure of the posterior part of the transplant. In retrospect, it is plausible that the OA changes in the knee joint already seen prior to surgery were too severe to justify inclusion in the study [22].

\section{Surgical procedure}

The surgical procedure is challenging as is all meniscal transplantations. With the extensive previous experience and knowledge in the use of the semitendinosus as an ACL graft [6-8], harvesting and preparation is well known. With the increasing awareness of meniscal root

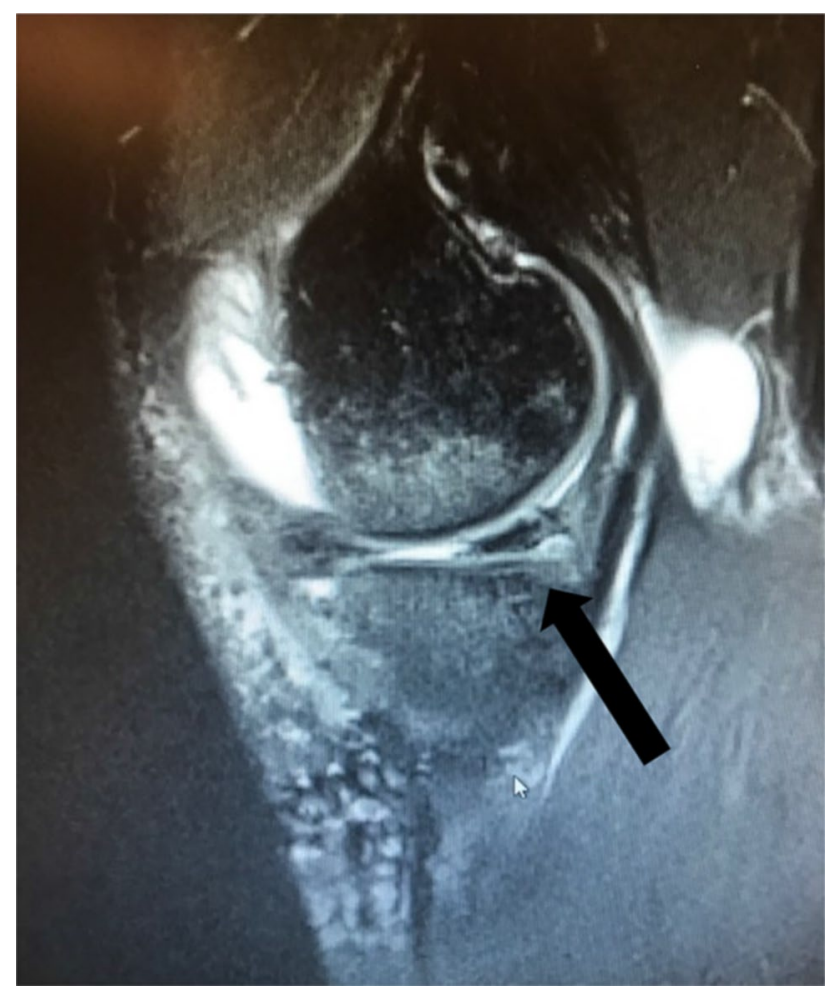

Fig. 5 Sagittal view of MRI T2-scan showing the posterior horn of a medial meniscus transplant (arrow) tears [5], tunnel positioning and drilling for meniscus roots has become a more common procedure.

\section{Patient outcome}

All four patients who had completed the 12-month followup reported improvement in Lysholm, KOOS symptoms subscale and Global score. This is of course a small material and even though the changes are statistically significant one can question its clinical relevance. In light of this technical report, it is, however, of importance to note that the patient's knee function did not deteriorate following surgery. No major complications were noted. Thus in the short-term perspective the safety of the procedure appears to be acceptable.

Johnson and Feagin reported non-favorable results after autograft tendon grafts as meniscus transplants [14]. Their procedures can, however, be considered salvage maneuvers as it would appear the patients already had joint changes that required a total knee joint replacement, which can explain why the results were not successful. When the OA development is too advanced, a meniscus transplant is unlikely to stop the progression, which is similar to our case no 2 (subsequently excluded from further follow-up), where the posterior part of the graft was removed at 12 months due to lack of ingrowth, graft instability and progression of OA [20].

However, with suitable intraarticular cartilage conditions a soft tissue graft could potentially serve well as a meniscus substitution as shown in the other cases in the present study. This is also in line with a recent case study that presented results from two cases, where the peroneus longus tendon was used as a meniscus transplant [25].

This study has several limitations. First and foremost the follow-up time is short, and the cohort is limited in size. It is difficult to draw any major conclusions on graft integrity and patient reported knee function on four patients after 1 year. One patient had completed the 24-month follow-up with still promising results. To be able to draw a sounder conclusion, more patients need to be included with a longer follow-up time.

Another limitation is that inclusion was not restricted to a certain BMI level. One patient included in the study had BMI > 35 which can possibly affect the outcome of that patients transplant and development of OA.

The patients in this study were not offered a MAT as alternative treatment. This is due to the low use of this method in our country as a result of logistical difficulties, costs and tradition. For further analysis it would be of interest to compare the outcome of this procedure with MAT.

With this limited number of cases it is impossible to determine whether this method is best used for medial or lateral meniscus transplantations. 


\section{Conclusion}

The use of autologous semitendinosus tendon as meniscus transplant seems to be a possible alternative to the methods used today. The patients included so far present improvement in weight bearing pain and quality of life.

Funding Open access funding provided by Karolinska Institute. No funding was received.

\section{Declarations}

Conflict of interest The authors declare that they have no conflict of interest.

Ethical approval The study was approved by the Regional ethical committee (Karolinska Institutet ID number: 2016/281-31/1) as stated in the beginning of the material and methods section.

Open Access This article is licensed under a Creative Commons Attribution 4.0 International License, which permits use, sharing, adaptation, distribution and reproduction in any medium or format, as long as you give appropriate credit to the original author(s) and the source, provide a link to the Creative Commons licence, and indicate if changes were made. The images or other third party material in this article are included in the article's Creative Commons licence, unless indicated otherwise in a credit line to the material. If material is not included in the article's Creative Commons licence and your intended use is not permitted by statutory regulation or exceeds the permitted use, you will need to obtain permission directly from the copyright holder. To view a copy of this licence, visit http://creativecommons.org/licenses/by/4.0/.

\section{References}

1. Andersson-Molina H, Karlsson H, Rockborn P (2002) Arthroscopic partial and total meniscectomy: a long-term follow-up study with matched controls. Arthroscopy 18:183-189

2. Ayala Mejias JD, Sciamanna RC, Muniesa MP, Pérez-España LA (2013) A case report of semitendinosus tendon autograft for reconstruction of the meniscal wall supporting a collagen implant. BMC Sports Sci Med Rehabil 5:4

3. Barenius B, Ponzer S, Shalabi A, Bujak R, Norlen L, Eriksson K (2014) Increased risk of osteoarthritis after anterior cruciate ligament reconstruction: a 14-year follow-up study of a randomized controlled trial. Am J Sports Med 42:1049-1057

4. Bendich I, Rubenstein W, Mustafa Diab M, Feeley B (2018) Evaluating meniscus allograft transplant using a cost-effectiveness threshold analysis. Knee 25:1171-1180

5. Bhatia S, LaPrade CM, Ellman MB, LaPrade RF (2014) Meniscal root tears: significance, diagnosis, and treatment. Am J Sports Med 42:3016-3030

6. Eriksson K, Anderberg P, Hamberg P, Olerud P, Wredmark $T$ (2001) There are differences in early morbidity after ACL reconstruction when comparing patellar tendon and semitendinosus tendon graft. A prospective randomized study of 107 patients. Scand J Med Sci Sports 11:170-177

7. Eriksson K, Hamberg P, Jansson E, Larsson H, Shalabi A, Wredmark T (2001) Semitendinosus muscle in anterior cruciate ligament surgery: morphology and function. Arthroscopy $17: 808-817$

8. Eriksson K, Larsson H, Wredmark T, Hamberg P (1999) Semitendinosus tendon regeneration after harvesting for ACL reconstruction. A prospective MRI study. Knee Surg Sports Traumatol Arthrosc 7:220-225

9. Getgood A, LaPrade RF, Verdonk P, Gersoff W, Cole B, Spalding T (2017) International Meniscus Reconstruction Experts Forum (IMREF) 2015 consensus statement on the practice of meniscal allograft transplantation. Am J Sports Med 45:1195-1205

10. Grassi A, Bailey JR, Filardo G, Samuelsson K, Zaffagnini S, Amendola A (2019) Return to sport activity after meniscal allograft transplantation: at what level and at what cost? A systematic review and meta-analysis. Sports Health 11:123-133

11. Harston A, Nyland J, Brand E, McGinnis M, Caborn DN (2012) Collagen meniscus implantation: a systematic review including rehabilitation and return to sports activity. Knee Surg Sports Traumatol Arthrosc 20:135-146

12. Hurley ET, Davey MS, Jamal MS, Manjunath AK, Kingery MT, Alaia MJ et al (2020) High rate of return-to-play following meniscal allograft transplantation. Knee Surg Sports Traumatol Arthrosc 28:3561-3568

13. Johnson LL (1993) The outcome of a free autogenous semitendinosus tendon graft in human anterior cruciate reconstructive surgery: a histological study. Arthroscopy 9:131-142

14. Johnson LL, Feagin JA Jr (2000) Autogenous tendon graft substitution for absent knee joint meniscus: a pilot study. Arthroscopy 16:191-196

15. Kim JM, Lee BS, Kim KH, Kim KA, Bin SI (2012) Results of meniscus allograft transplantation using bone fixation: 110 cases with objective evaluation. Am J Sports Med 40:1027-1034

16. Kohn D (1993) Autograft meniscus replacement: experimental and clinical results. Knee Surg Sports Traumatol Arthrosc $1: 123-125$

17. Kohn D, Wirth CJ, Reiss G, Plitz W, Maschek H, Erhardt W et al (1992) Medial meniscus replacement by a tendon autograft. Experiments in sheep. J Bone Jt Surg Br 74:910-917

18. LaPrade RF, Wills NJ, Spiridonov SI, Perkinson S (2010) A prospective outcomes study of meniscal allograft transplantation. Am J Sports Med 38:1804-1812

19. Lee BS, Kim HJ, Lee CR, Bin SI, Lee DH, Kim NJ et al (2018) Clinical outcomes of meniscal allograft transplantation with or without other procedures: a systematic review and meta-analysis. Am J Sports Med 46:3047-3056

20. Lee DH, Kim SB, Kim TH, Cha EJ, Bin SI (2010) Midterm outcomes after meniscal allograft transplantation: comparison of cases with extrusion versus without extrusion. Am J Sports Med 38:247-254

21. Lutz C, Dalmay F, Ehkirch FP, Cucurulo T, Laporte C, Le Henaff $\mathrm{G}$ et al (2015) Meniscectomy versus meniscal repair: 10 years radiological and clinical results in vertical lesions in stable knee. Orthop Traumatol Surg Res 101:S327-331

22. Mahmoud A, Young J, Bullock-Saxton J, Myers P (2018) Meniscal allograft transplantation: the effect of cartilage status on survivorship and clinical outcome. Arthroscopy 34:1871-1876

23. McCormick F, Harris JD, Abrams GD, Hussey KE, Wilson H, Frank R et al (2014) Survival and reoperation rates after meniscal allograft transplantation: analysis of failures for 172 consecutive transplants at a minimum 2-year follow-up. Am J Sports Med 42:892-897

24. Milachowski KA, Weismeier K, Wirth CJ (1989) Homologous meniscus transplantation. Experimental and clinical results. Int Orthop 13:1-11

25. Milenin O, Strafun S, Sergienko R, Baranov K (2020) Lateral meniscus replacement using peroneus longus tendon autograft. Arthrosc Tech 9:e1163-e1169 
26. Novaretti JV, Patel NK, Lian J, Vaswani R, de Sa D, Getgood A et al (2019) Long-term survival analysis and outcomes of meniscal allograft transplantation with minimum 10-year follow-up: a systematic review. Arthroscopy 35:659-667

27. Paxton ES, Stock MV, Brophy RH (2011) Meniscal repair versus partial meniscectomy: a systematic review comparing reoperation rates and clinical outcomes. Arthroscopy 27:1275-1288

28 Petersen W, Karpinski K, Bierke S, Müller Rath R, Häner M (2021) A systematic review about long-term results after meniscus repair. Arch Orthop Trauma Surg. https://doi.org/10.1007/ s00402-021-03906-z

29. Pujol N, Barbier O, Boisrenoult P, Beaufils P (2011) Amount of meniscal resection after failed meniscal repair. Am J Sports Med 39:1648-1652

30. Rongen JJ, Hannink G, van Tienen TG, van Luijk J, Hooijmans CR (2015) The protective effect of meniscus allograft transplantation on articular cartilage: a systematic review of animal studies. Osteoarthr Cartil 23:1242-1253

31. Rosso F, Bisicchia S, Bonasia DE, Amendola A (2015) Meniscal allograft transplantation: a systematic review. Am J Sports Med 43:998-1007

32. Saltzman BM, Bajaj S, Salata M, Daley EL, Strauss E, Verma N et al (2012) Prospective long-term evaluation of meniscal allograft transplantation procedure: a minimum of 7-year follow-up. J Knee Surg 25:165-175

33. Samitier G, Alentorn-Geli E, Taylor DC, Rill B, Lock T, Moutzouros V et al (2015) Meniscal allograft transplantation. Part 2: systematic review of transplant timing, outcomes, return to competition, associated procedures, and prevention of osteoarthritis. Knee Surg Sports Traumatol Arthrosc 23:323-333

34. Seitz AM, Dürselen L (2019) Biomechanical considerations are crucial for the success of tendon and meniscus allograft integration-a systematic review. Knee Surg Sports Traumatol Arthrosc 27:1708-1716

35. Shelbourne KD, Dersam MD (2004) Comparison of partial meniscectomy versus meniscus repair for bucket-handle lateral meniscus tears in anterior cruciate ligament reconstructed knees. Arthroscopy 20:581-585
36. Smith NA, Parkinson B, Hutchinson CE, Costa ML, Spalding T (2016) Is meniscal allograft transplantation chondroprotective? A systematic review of radiological outcomes. Knee Surg Sports Traumatol Arthrosc 24:2923-2935

37. Sommerlath K, Gillquist J (1992) The effect of a meniscal prosthesis on knee biomechanics and cartilage. An experimental study in rabbits. Am J Sports Med 20:73-81

38. Stein S, Hose S, Warnecke D, Gentilini C, Skaer N, Walker R et al (2019) Meniscal replacement with a silk fibroin scaffold reduces contact stresses in the human knee. J Orthop Res. https://doi.org/ 10.1002/jor.24437

39. Stein T, Mehling AP, Welsch F, von Eisenhart-Rothe R, Jager A (2010) Long-term outcome after arthroscopic meniscal repair versus arthroscopic partial meniscectomy for traumatic meniscal tears. Am J Sports Med 38:1542-1548

40. Stevenson C, Mahmoud A, Tudor F, Myers P (2019) Meniscal allograft transplantation: undersizing grafts can lead to increased rates of clinical and mechanical failure. Knee Surg Sports Traumatol Arthrosc 27:1900-1907

41. Verdonk P, Beaufils P, Bellemans J, Djian P, Heinrichs EL, Huysse W et al (2012) Successful treatment of painful irreparable partial meniscal defects with a polyurethane scaffold: two-year safety and clinical outcomes. Am J Sports Med 40:844-853

42. Waugh N, Mistry H, Metcalfe A, Loveman E, Colquitt J, Royle $P$ et al (2019) Meniscal allograft transplantation after meniscectomy: clinical effectiveness and cost-effectiveness. Knee Surg Sports Traumatol Arthrosc 27:1825-1839

43. Young J, Tudor F, Mahmoud A, Myers P (2017) Meniscal transplantation: procedures, outcomes, and rehabilitation. Orthop Res $\operatorname{Rev} 9: 35-43$

Publisher's Note Springer Nature remains neutral with regard to jurisdictional claims in published maps and institutional affiliations. 